\title{
Assessing pre-service teachers' professional identity construction in a three-phase teacher education program in Iran
}

\author{
Fariba Haghighi Irani, Azizeh Chalak ${ }^{*}$ and Hossein Heidari Tabrizi
}

\footnotetext{
*Correspondence: azichalak@gmail. com

Department of English, Isfahan (Khorasgan) Branch, Islamic Azad University, Isfahan, Iran
}

\begin{abstract}
The critical role of teachers suggests that assessing teacher identity construction helps teacher educators understand the changes in teachers and design materials in harmony with their needs in teacher education programs. However, only a few studies have focused on assessing pre-service teachers' identity in the long term in Iran. To address this gap, the contribution of a pre-service teacher education program consisting of three phases, namely engage, study, and activate to the professional identity construction of eight pre-service teachers in an institute in Tehran was assessed. Pre-course and post-course interviews, two reflective essays, ten observation notes, and two teaching performances were gathered over a year and analyzed as guided by grounded theory and discourse analysis. Findings revealed two significant changes in the participants' identities when they transitioned from engage to study and from study to activate phases that yielded study phase as the peak of the changes. Overall, three major shifts were identified in the participants' identities: from a commitment to evaluation towards a commitment to modality, from one-dimensional to multi-dimensional perceptions, and from problem analysis to problem-solving skills. Current findings may facilitate teacher identity construction by designing local programs matching the needs of pre-service teachers. It may also assist teacher educators by assessing the quality of teachers' performance and developing teacher assessment tools.
\end{abstract}

Keywords: Assessing identity construction, Pre-service teacher, Professional identity construction, Teacher assessment, Teacher education program, Teacher professional identity

\section{Introduction}

The significant role of teachers suggests assessing the process of teacher professional identity (TPI) construction during the primary field of teacher education (TE) programs (Hanna, Oostdam, Severiens, \& Zijlstra, 2020). The literature reveals a strong connection between the quality of teaching and TPI (Cattley, 2007; Trent, 2010). Palmer's (1998), p.13 argument that "Good teaching comes from the identity and integrity of teachers." implies the fact that is supported by teachers' honesty in what they believe in.. In other words, good teaching is an integration of multiple factors including

(c) The Author(s). 2020 Open Access This article is licensed under a Creative Commons Attribution 4.0 International License, which permits use, sharing, adaptation, distribution and reproduction in any medium or format, as long as you give appropriate credit to the original author(s) and the source, provide a link to the Creative Commons licence, and indicate if changes were made. The images or other third party material in this article are included in the article's Creative Commons licence, unless indicated otherwise in a credit line to the material. If material is not included in the article's Creative Commons licence and your intended use is not permitted by statutory regulation or exceeds the permitted use, you will need to obtain permission directly from the copyright holder. To view a copy of this licence, visit http://creativecommons.org/licenses/by/4.0/. 
teachers' professional self, teaching competence, and practice. In addition, good teaching is encouraged by an effective teacher development curriculum (Korthagen, Loughran, \& Russell, 2006) leading to strong teacher identity.

Moreover, the complexity of the professional identity of teachers has been defined as an integration of one's previous and present experiences during the practicum and personal beliefs which will affect their future activities, behavior, and decision making as teachers (Chong, Low, \& Goh, 2011). Due to the complicated nature of this phenomenon, recent studies suggest more investigations on the assessment of how TPI is shaped and reshaped in TE over time (Prabjandee, 2020; Varghese, Morgan, Johnston, \& Johnson, 2005). Researchers believe that assessing this process can help teacher trainers to augment their awareness of the tensions in teacher trainees and to be able to select and design materials in harmony with their needs in TE programs (Beijaard, Meijer, \& Verloop, 2004; Pennington \& Richards, 2016). This movement guided researchers to incorporate pedagogical tools in the TE programs to foster the process of the formation of teachers' identity (Cattley, 2007; Maclean \& White, 2007) or develop assessment tools to assess student teachers' professional identity and teaching quality (Hanna et al., 2020). However, they have not explicitly and systematically addressed how teacher identity is constructed over time.

\section{Assessing TPI in TE}

Studies suggest that TPI is an ongoing challenge; that it passes through a maturation process and is created and recreated through meaningful practices especially at the early stages of the practicum (Chong et al., 2011; Kanno \& Stuart, 2011). Furthermore, the complexity of teacher identity indicates an interaction between internal and external factors such as emotions, agency, beliefs, confidence, and competence, and contextual components including student-teachers' relationship with their mentor, colleagues, and students (Beauchamp \& Thomas, 2009; Izadinia, 2013). Student teachers enter the teaching profession with their personal identity and previous experiences that can influence the construction of self-awareness either encouraging or hindering it during the first year of teacher education. These contradictions may lead them to experience tensions, feel uncertainty and find teaching a difficult career (van der Wal, OolbekkinkMarchand, Schaap, \& Meijer, 2019). This echoes the belief that the professional identity of teachers is a unique concept difficult to define and assess (Hanna et al., 2020; Maclean \& White, 2007).

To assess and document the developmental stages of trainees' professional identity, the TE curriculum has benefited from qualitative and quantitative assessment tools. Among a plethora of qualitative studies, for instance, Antonek, McCormick, and Donato (1997) suggest that portfolio data can be employed as an assessment tool to trace teachers' growth and development. In a case study, they documented two pre-service teachers' identity construction through incorporating portfolios in a TE program and found that portfolios can provide teacher educators with a variety of data as an assessment tool during the practicum. Their findings indicated that portfolios can be used as both a self-reflection instrument to assess the trainees' teaching quality and improvement over time and as a comprehensive mediation 
tool in educational fields. They also argued that portfolios help pre-service teachers to transition from being a student to becoming a teacher.

More recently, Trent and Shroff (2013) explored the struggles of six Chinese undergraduate students in constructing their identities by assessing an e-portfolio method using in-depth interviews for 8 weeks. In this study, the participants could negotiate their professional identity through engagement in the electronic portfolio during their teaching course. Both studies signify the role of portfolio assessment in tracing the process of TPI construction. Similarly, some other researchers used journal writing (e.g. Abednia, Hovassapian, Teimournezhad, \& Ghanbari, 2013; Birello, Royer, \& Pluvient, 2011), video reflection (e.g. Maclean \& White, 2007), and narratives (e.g. Prabjandee, 2020) as assessment tools.

It appears that most assessment tools which exist focus on secondary school environments and are not applicable to designing or assessing pre-service TPI. (Hanna et al., 2020; Hanna, Oostdam, Severiens, \& Zijlstra, 2019). In a 2013 paper, Friesen and Besley attempted to anticipate the developmental process of TPI in the primary year of TE through a Likert scale. They examined the amalgamation of personal and social identity, generativity, and the development of teacher identity during the first year of education in an attempt to find which aspects can predict the student teachers' identity development in the first year. Surprisingly, the results of the study revealed a high level of teacher identity in two groups of participants: those who were parents and those who were experienced in working with children. Furthermore, they found the personal identity as an anticipator aspect of first-year student teachers.

In a recent research, Hanna et al. (2020) developed an instrument based on four major domains of teacher identity: motivation, self-efficacy, self-image, and task perception. Despite the efficiency of this assessment scale, researchers point to a few limitations, most significant of which is its use of quantitative studies domains. They recommended that other domains such as resilience and future time perspective as well as domains taken from qualitative research be included in further studies because certain domains are not stable. Although the results were based on extensive systematic analyses of assessment scales, the inherent complexity of TPI (van der Wal et al., 2019) indicates that using a list of quantitative components to measure teacher identity is inadequate; a thorough assessment of teacher identity requires additional evaluation criteria.

\section{TE as an emergent context of TPI}

Taking TE curriculum as an emergent point of TPI (Korthagen, 2004), some other scholars believe that redesigning TE programs to integrate interactive teacher training stimulates shaping the professional identity of pre-service teachers (Beauchamp \& Thomas, 2009; Tao \& Gao, 2018). It appears that the formation of teacher identity is worth being explicitly assessed and explored in a meticulously designed TE program.

In this case, implementing a systematic curriculum that is responsive to the needs of the student teachers and teacher educators, and the complexities of various contexts has been suggested as a fundamental goal in TE (Lee, 2005). In order for student teachers to discover their selves, become self-reflective, and learn how to become a 
teacher, TE programs need to be revised and redesigned and critical activities planned in a way that makes a meaningful context (Yazan, 2019). Such a context can be developed by focusing on reflection, engagement, and practice as fundamental principles.

As the major context of professional identity construction, TE has frequently been criticized for different reasons. Some scholars assert that TE programs do not meet the needs of the new generations of teachers or the students in real contexts (Korthagen et al., 2006). Freeman (1989) argues that TE lacks a coherent framework that has led to the proliferation of fragmented materials and models.). He believes that one reason for this unfocused approach to teaching English as a Foreign Language, is the belief that a teacher's verbal proficiency in English is sufficient in making her/him a competent and effective instructor of EFL- "anyone who speaks it can teach it" (p. 27). In a parallel argument, Kumaravadivelu (2012) has explicitly referred to current TE programs as a focal source of teachers' difficulty in thinking and acting directly. In Iran, a recent study concludes that courses are designed based on trainer's intuition rather than trainees' needs. While some courses focus on theoretical aspects of teaching methods, other courses focus on only practical aspects that leads this to an unbalanced program to train qualified language teachers (Ganji, Ketabi, \& Shahnazari, 2018). All of the issues mentioned above continue to persist, to varying degrees, in programs of pre-service TE. As a consequence, to counterbalance the diversity of the programs, some practitioners have called for common purposes and principles (Bigelow \& Walker, 2004).

\section{TE in Iran}

In Iran, although the educational system in training language teachers has witnessed revisions supporting changes in language teaching methodology, practitioners report several shortcomings on a variety of issues. They characterize TE in Iran as a positivistic, transmission-oriented, theoretical, and de-contextualized program (Naseri Karimvand, Hessamy, \& Hemmati, 2014; Nezakat-Alhosseini \& Ketabi, 2013). Consequently, to train quality teachers and to harmonize teacher development programs with rapid changes in new technology and methodology in language teaching, Kennedy (2015) recommends that the TE curriculum be shifted from a trainer-centered to traineecentered model.

Within the Iranian context, a large body of literature has investigated the development of TPI in terms of its components including teachers' perceptions (Rashidi \& Mansourzadeh, 2017), factors influencing the formation of professional identity (Tajeddin \& Khodarahmi, 2013), EFL teachers' self-esteem (Motallebzadeh \& Kazemi, 2018), and peer-coaching and its impact on learners' academic achievement (Abbasian \& Karbalaee Esmailee, 2018). All of the above scholars are focusing specifically on the components of TPI in the TE programs as opposed to student teachers in general. Some other scholars incorporated critical pedagogy in TE programs to examine the tensions associated with TPI. For instance, Abednia's (2012) findings revealed three major shifts in TPI indicating critical autonomy and change in emphasis He mentioned that understanding dynamics, changes, and the multi-dimensionality of the nature of such an abstract construct like TPI requires critical and transformative-oriented studies in a longitudinal qualitative paradigm. Likewise, a recent study by Sardabi, Biria, and 
Ameri Golestan (2018) evidenced a significant change in in-service teachers' professional identity towards a humanistic perception of teaching.

Although there is general acknowledgment of a need to change in terms of the course content of TE programs (Kennedy, 2015; Nezakat-Alhosseini \& Ketabi, 2013), the literature does not propose significant transformations. Also, despite a large number of calls from practitioners who highlighted the need for longitudinal studies to explore the complexities of teacher identity (Trent, 2011; Yuan \& Lee, 2014), until recently, long term studies on assessing the process of this significant construct in pre-service teachers and on a specific sequence of the materials in TE curriculum is lacking. Therefore, a need to assess the impact of the sequence of the materials in a TE curriculum on the development, formation and reformation of EFL pre-service TPI in Iran was perceived.

The current study adds to the abovementioned understandings by assessing the process of pre-service teachers' identity formation in the context of a three-phase TE program over 1 year. Centralizing assessing of both process-oriented and productoriented approaches as well as linking theoretical and practical contents can contribute to our awareness of the focal nature of TPI and the TE curriculum. This understanding will have practical implications for teacher educators, curriculum developers, and stakeholders on how to design materials to promote TE programs. Besides, tracking and assessing the identity formation of pre-service teachers from the initial to the exit stage of a course specifically for training teachers rather than being part of a university program can unveil the maturation process of pre-service teachers' learning to teach and offer practical implications on how to enhance the construction of teacher identity. This study helps teacher educators understand the relations between professional identity tensions and the content of the stages in a TE program.

Encouraged by the findings and recommendations of previous studies, the research questions were formulated as:

1. How is pre-service TPI constructed in each phase of an EFL three-phase TE curriculum in Iran?

2. What factors facilitate the process of becoming a teacher in a three-phase TE curriculum in Iran?

\section{Methods}

\section{Design of the Study}

The nature of identity formation encouraged the researchers to employ a qualitative case study design within the framework of the social constructivist approach because teacher identity is not a ready-made construct, but is developed through interactions over time. In this research, the emergence and development of TPI were assessed in a three-phase TE program named Engage, Study, and Activate (ESA) in a higher education institute in Tehran.

\section{ESA teacher education curriculum}

ESA teacher education curriculum was a non-compulsory program designed for a higher education institute in Tehran in 2014. It was aimed at training highly- 
qualified English teachers and the study sources were selected based on the most up to date international references. All the steps of the research were run in a natural setting. This behavioral research, in its entirety, was carried out in a regular classroom setting, making certain that the participants' behavior was not being influenced in any way by the researcher's expectations, namely Halo and Hawthorne effects (Mackey \& Gass, 2005). The advantage of the natural setting suggests that this curriculum was not developed for the sake of the research or was not selected as a part of a program. It was an existing three-phase TE curriculum that was designed for institutional purposes based on the courses offered by the Ministry of Science, Research, and Technology (MSRT).

The materials of Phase One (engage) were focused on the knowledge of the language and teaching methodology. In this phase, student teachers studied instructor chosen sources, watched relevant videos, described and analyzed teaching models, and discussed these critically in pairs or groups in the class.

Phase Two (study) integrated theory and practice through consolidating learned materials from the previous stage with practical guides in teaching language skills and components, and teaching performances. In other words, student teachers conducted macro and micro-teaching units by synthesizing their knowledge derived from the engage phase. Moreover, they were required to study and perform some teaching techniques and strategies. After each performance, trainees participated in self- assessment and peer-assessment sessions. These sessions allowed the trainees to identify the positive features of the performances, as well as the areas of growth in their performances. Meanwhile, the teacher educator systematically explained the purpose of each activity, instructed, and guided the performances and the discussions before the activities and gave feedback afterward. To take the constructivist approach as a model, the teaching practices started with micro-teaching units in short scales $(10 \mathrm{~min})$ of focused teaching. These practices were allocated to small bits of discrete language skills and components to enable the trainees to integrate them to perform macro teaching units in longer scales $(20$ and $30 \mathrm{~min})$ at the end of this phase.

To enable the pre-service teachers to connect and activate topics learned during the previous two phases, Phase Three (activate) focused on educational psychology and assessment tasks. The trainees' activities and reflections were encouraged by studying relevant topics of learning psychology theories and assessment derived from the engage and study phases, developing relevant language and assessment tasks, and reflecting and discussing with peers guided by the trainer. It was assumed that this type of framework of TE program could help teacher educators be more flexible by incorporating varieties of activities into each phase and assist teacher trainees to negotiate their professional identities. Presumably, a recursive rather than a linear program model allows student teachers to activate their knowledge of the previous stages before studying new material in a subsequent phase. Figure 1 illustrates the three phases in ESA Teacher education curriculum.

The dual emic role of the researcher as a teacher educator and a researcher indicates her active role in both classroom activities and the research steps. In brief, the study started in February 2017, ended in March 2018, and lasted 44 weeks over 1 year. The classes were held once a week for 5 hours. 


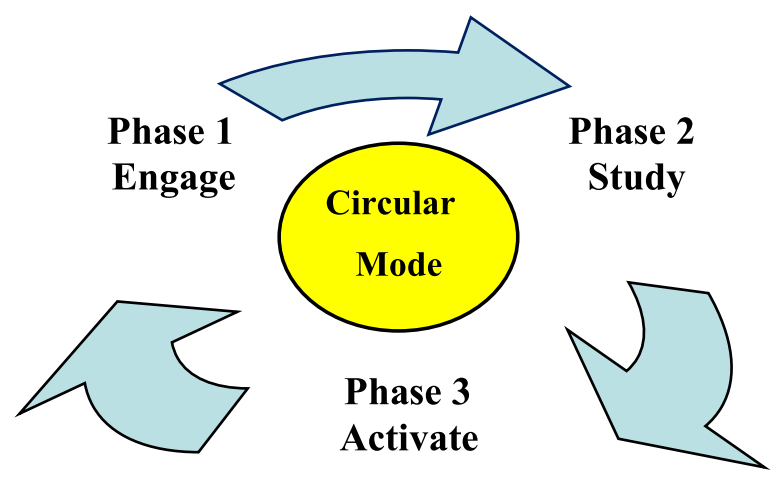

Fig. 1 A schematic representation of the three-phase teacher education program

\section{Participants}

The participants of the present study were eight females, between 18 and 38-yearolds who had not experienced any teaching classes before the practicum and launched their training courses as pre-service teachers. They came from different academic majors and degrees and all spoke Persian as their mother tongue. They were selected purposefully according to the recruitment criteria of the institute for the ESA TE program. The criteria for participants' selection were to be at an advanced level of proficiency and be interested in teaching English. Although, the participants were of different majors and ages and were all of the same gender, it was not the purpose of the study to include such features in their teacher identity development. Therefore, all of the eight enrolled candidates were recruited for the research.

All of the participants signed a formal informed consent document which confirmed that their identifiable information would be kept confidential by assigning pseudonyms, and their responses to the interview questions and reflective prompts would not interfere in their final evaluation and score. Table 1 represents the configuration of the participants with their pseudonyms.

\section{Instruments}

To enhance the trustworthiness of the research instruments and to be able to collect in-depth data to assess the process of identity formation, data triangulation techniques in a portfolio method were employed (Ary, Jacobs, Irvine, \& Walker,

Table 1 A configuration of the participants with their Pseudonyms

\begin{tabular}{llll}
\hline Participants & Age & Degree & Major \\
\hline NA & 24 & BS & Mechatronics Engineering \\
AF & 38 & BA & Natural Sciences \\
AR & 20 & BS & Computer Engineering \\
PA & 21 & BS & Medical Engineering \\
ME & 28 & MA & Management \\
SA & 26 & MA & MBA \\
ZA & 18 & BA & Eco-Insurance Management \\
HE & 23 & MA & Management \\
\hline
\end{tabular}


2019; Riazi, 2016). Three types of instruments including oral, written, and video forms were employed. The instruments were designed and responded to in English.

Oral forms were an open-ended pre-course interview and one focus group discussion as a post-course interview. Both interviews were semi-structured, in English, and were developed according to Kelchtermans' (1993) conceptualization of TPI including task perception, self-esteem, job motivation, self-image, and future perspective because it is assumed that these main domains can be employed as a checklist for assessing the developmental process of the professional identity of teachers (Hanna et al., 2019). Then, to test trustworthiness, the interview questions were put to a similar group of student teachers in the same institute by the researcher, and, based on responses minor changes were made in the wording of the questions.

Written instruments were two reflective essays and ten observation notes. The reflective essays were planned to assess the changes in pre-service TPI in each phase. To help organize and focus their responses and reflections, six prompts were developed and given to the participants. These prompts incorporated the teacher role awareness data collected from the participants in previous phases.

To evidence the progress of the trainees' professional identity and to help credibility and confirmability of the research findings, an observation checklist was formulated in six main sections based on the course materials of Phase One and Two. In this form, the participants were required to report what they observed regarding each item and in the comment section, they were asked to comment reflectively guided by the question: 'If you were the teacher of this classroom, how would you improve teaching?' at the end of the checklist.

Furthermore, to enable the researcher to assess the discourse and behavior of preservice teachers, two sessions of their teaching practices as a supplementary data collection tool were videotaped and analyzed supported by the idea that changes in teachers' identities are manifested in student teachers' teaching and practices (Izadinia, 2013). The collection of data for each phase is explained below.

\section{Data collection procedure}

The data were collected over a period of 1 year. This procedure was initiated on the first day of Phase One (engage) with a pre-course interview to identify the initial state of the trainees' professional identity. Further, to assess the emergence and development of professional identity over this phase, trainees completed the first reflective essay on the last day. As mentioned above, all students signed an informed consent and were assured that their responses in the reflective essay would not have any influence on their final grade in order to secure their honest and authentic views.

In Phase Two (study), the participants were required to observe ten English teaching classes as part of their field training concurrently with their weekly classes and were asked to fill out the observation checklist. The comment section of this form as it was mentioned in the Instruments section above, was taken as observation notes that were analyzed and interpreted. (Farrell, 2011; Kennedy, 2015). In addition, the last two sessions of this Phase were allocated to student teachers' performances on teaching different language skills and were analyzed to enable the researcher to assess trainees' teaching in terms of discourse and behavior. 
Finally, to assess the final changes and shifts in Phase Three (activate), 1 week before the final session, the second reflective essay was sent to the participants by email to be completed carefully and thoughtfully. Also, in the last session of this phase, to ensure the credibility of the procedure, the participants attended a one-hour semi-structured focus group discussion to assess the transition of their professional identity in detail. Their responses to questions asked during the pre-course interview were compared with their responses during this final interview. These were analyzed to determine achievement level of teacher professional identity. Figure 2 illustrates the data collection procedure explicitly.

\section{Data analysis procedure}

To ensure the credibility of findings, the triangulation method was applied (Ary et al., 2019). The collected data were analyzed using Grounded Theory (GT) (Glaser \& Strauss, 1967) as an overall approach and a technique well-suited to the purpose of the present study. However, regarding the complex process of identity construction and being cognizant of the fact that GT does not provide adequate tools to accurately assess language changes over time, Fairclough's (2003) identity-in-discourse model was incorporated into the GT as a concurrent Discourse Analysis tool.

According to Fairclough (2003), the way people identify themselves through texts is a significant part of who they are. He examines 'modality' in terms of using modal verbs, adverbs, adjectives, mental process clauses, and hedges, and explores 'evaluation' in terms of what is desirable and undesirable. In this case, 'evaluation' is displayed in evaluative statements including evaluative adjectives, adverbs, and affective mental process verbs. In oral presentations, he also considers markers of modularization in terms of degrees of commitments that are presented in a tone of the speakers' oral delivery whether ideas are said in a hesitant, tentative, confident, or assertive tone.

Accordingly, to analyze the present data, at the opening code level of GT, attempts were made to break down the collected data including oral, written, and video forms into units of analysis such as phrases and sentences where the participants presented their commitment to teaching in terms of modality and evaluation. Codes were assigned to the emerging units that included modal verbs, adverbs, and adjectives such as 'should, possibly, possible, can, may, might, will, would ...' and mental process

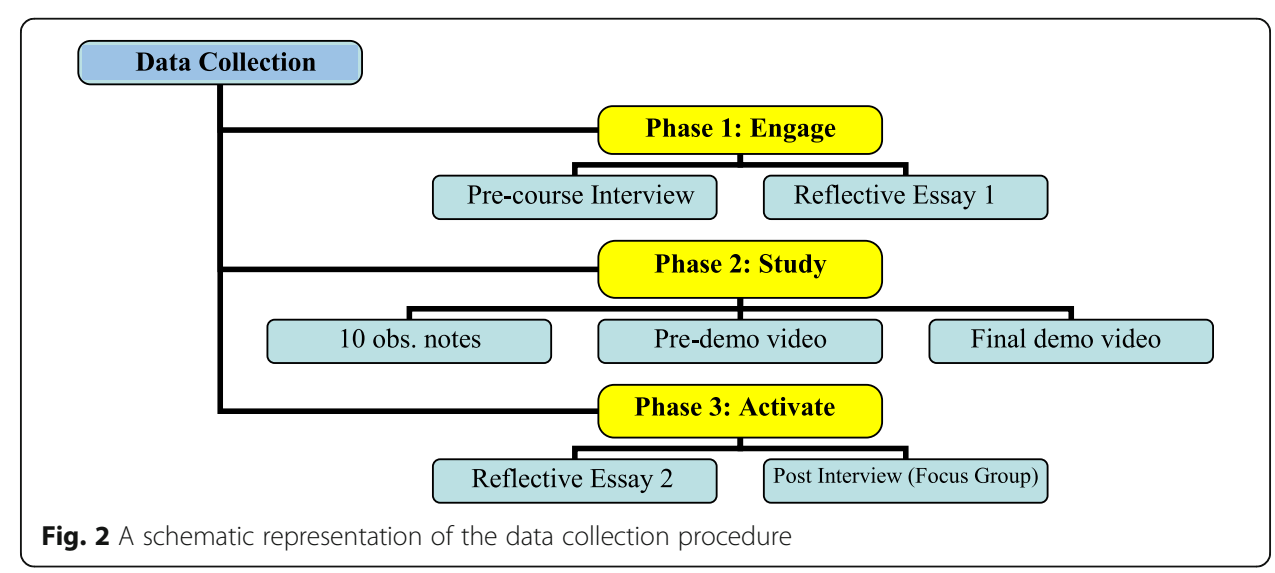


markers such as 'I think, it seems to me, in my opinion, I understand, I realize ... ' Also, units that included value markers presenting evaluation in terms of the participants' desirability and undesirability, likes and dislikes, good or bad ideas such as 'wonderful, great, important, significant, ...' and affective mental process markers such as 'I love, I like, I feel happy, I'm satisfied, ... ' were coded.

Then, the second step of GT, the axial coding, was performed through multiple reviews of the coded units extracted from the previous level. Thus, relevant units were juxtaposed in a table to find meaningful relationships between codes and prepare them for the next stage.

In the last stage of the data analysis, the selective level, the focal meaningful units were identified, reorganized, and compared conceptually in terms of each gathered data in each phase throughout the program. Lastly, the units selected in this stage were categorized as modality units of assertion, truth, demand, offer, obligation, necessity, mental process, and evaluation units of affective mental process and values. Then, the extracted categories were read over and over and compared and refined at different times by the researcher and one expert to ensure the trustworthiness of the selected categories.

In order to assess the changes in the process of identity construction, the number of occurrences of the categorized codes was tabulated in each type of data. Then, the percentages of commitments to modality and evaluation were recorded but the codes that appeared less than three times, were not considered (Farrell, 2011). Finally, the recorded percentages of the collected data for each participant were compared throughout the process of identity development in each phase and the turning points across the program were identified. Thus, changes in the professional identity of eight participants were assessed and interpreted. It is worth mentioning that to establish credibility and to protect the researcher from pre-determined impressions, triangulation as a cross-validating technique in data collection and data analysis tools was utilized (Dörnyei, 2007; Riazi, 2016).

\section{Results}

To assess how eight participants' professional identities were constructed in the ESA teacher education curriculum, the findings are explained in terms of Fairclough's (2003) model of identity formation regarding each phase and the specific assessment tool. Then, the major emergent changes through GT will be interpreted.

TPI construction in discourse

\section{Phase one (engage)}

In the pre-course interview, when the participants were asked about their reasons for selecting this course to learn how to teach, generally they referred to their love of teaching English and tended to use more value statement markers (36.5\%) rather than modality markers (24\%). For instance, NA's opinion represents the attitudes of most trainees through using markers such as 'teaching is rewarding', 'I'm quite happy', and 'I've always loved teachers who are somewhat strict and have a plan.' Also, her strong statements of the mental process such as 'I do think' underscores her commitment to evaluate the teaching profession positively. 
The analysis of RE1 resulted in 174 meaningful units categorized into the assertion, mental process, obligation, demand, and offer (modality), and value statements, and affective mental process (evaluation). Accordingly, the total frequency of using modality and evaluation markers indicated a $94 \%$ measure of commitment which presents a significant increase compared to the measure of $60.5 \%$ at the beginning of the course. See Table 2 Commitment to Modality and Evaluation in Each Phase.

For instance, a positive evaluation of trainees' self-images appeared when asked to compare their feeling as a teacher to that of the first day. They used adverbs such as 'totally different' to evaluate their improvement as a teacher. As SA stated: "Now, my gestures and the way I sit are like a real teacher." And PA asserted: "I feel I have grown up and I'm eager for the rest of the way."

\section{Phase two (study)}

Stepping into Phase Two (S), participants elaborated on the commitment to modality using more truth, necessity, obligation, and offer markers encouraged by incorporating practical activities and field training to Phase Two. Likewise, the ultimate level of total identification $(100 \%)$ marked this phase as the peak of a dramatic change in the professional identity of the participants. It is worth noting that since no significant changes were evident in any of the observations recorded, only four observations from each participant were analyzed: their first and second observation and their last two observations.

The analysis of the first two observation notes suggested that student teachers generally underpinned their comments by using hypothetical offers. In other words, they used fewer value markers and affective mental process markers. However, the last two observations recorded displayed hypothetical offers supported by stronger markers such as 'I would never let my students use L1'. Moreover, pre-service teachers stated their commitment to act with more certainty using more assertion and demand markers along with mental process statements. For example, PA and AR's use of certain modality markers (I know, Should) supports the findings in Phase Two of this study.

To ensure the trustworthiness of the findings and to assess the professional identity changes which were not displayed in other data collection tools, pre-service teachers' behavior at the time of teaching and their voice in terms of hesitant, confident, and assertive tone were assessed as complementary evidence. Fairclough (2003), p. 171 argues, "Intonation and other aspects of oral delivery are also relevant to a speaker's degree of commitment; whether things are said in a hesitant, tentative, confident or assertive tone." Almost all of the participants demonstrated significant progress, throughout the Study Phase, by being physically active, and demonstrating self-confidence through

Table 2 Commitment to modality and evaluation in each phase

\begin{tabular}{lllllllll}
\hline ESA Phases & Phase 1(E) & & & Phase 2 (S) & & \multicolumn{2}{l}{ Phase 3 (A) } \\
\cline { 2 - 3 } Instruments & Pre-int. & RE1 & & Obs 1 & Obs 2 & & RE2 & Post-int. \\
\hline Units & 63 & 174 & & 53 & 40 & & 199 & 245 \\
Modality & $15(24 \%)$ & $43(25 \%)$ & & $30(57 \%)$ & $30(75 \%)$ & & $93(47 \%)$ & $91(37 \%)$ \\
Evaluation & $23(36.5 \%)$ & $120(69 \%)$ & & $16(30 \%)$ & $10(25 \%)$ & & $98(49 \%)$ & $77(31.5 \%)$ \\
Total & $38(60.5 \%)$ & $163(94 \%)$ & & $46(87 \%)$ & $40(100 \%)$ & & $191(96 \%)$ & $168(68.5 \%)$ \\
\hline
\end{tabular}


proper tone of voice, body language, eye-contact and movement This supports Özmen's (2010) claim that pre-service teachers' non-verbal behavior can be developed and improved during practicum by field training. Moreover, once given the required criteria, teachers demonstrated a significant improvement in designing their own unique teaching language skills.

Acquiring self-confidence through actions, observations, reflective discussions, and micro-teaching performances in Phase Two (S) enabled teacher trainees to integrate creatively and deliberately the knowledge learned through the Engage and Study phases with other video resources from online international classes in contexts such as their final performance sessions.

\section{Phase three (activate)}

In the last phase of the study (A), analyses of the RE2 and the focus group discussion suggested that the pre-service teachers failed to go beyond their level of commitment to modality and evaluation comparing to the Engage Phase. In other words, they experienced a sharp decline in making the transition from Study to Activate.

For example, in response to the motivation of continuing teaching as a profession compared with the starting day of the course, participants generally evaluated themselves and their changes over the program in a positive manner through using strong evaluative terms such as 'totally changed', 'really enjoyed', and 'a crucial job'. In addition, 'perception of tasks' as an identity formation concept was emerged through evaluative terms such as 'effective teacher' and 'brilliant behavior'. NA, however, thought that some of the teaching patterns were not easy to follow through - that's not an easy task'.

Students' positive responses indicate that they perceived themselves as successfully in the process of transitioning from a student teacher to a professional teacher during the program. Another piece of evidence to the abovementioned findings can be represented in response to their perception of turning from a student teacher to a professional teacher throughout the program. The participants could describe their changes and evaluate the turning points in their attitudes through self-description and positive selfimages. Almost all of them agreed that they felt a great change in the first transitional stage from Phase One to Phase Two.

Furthermore, pre-service teachers' commitment to evaluation and modality was observed in their responses to focus group interview items. In response to the question how did the design of the three phases help them learn to teach?, pre-service teachers presented their commitment to evaluation through using value markers such as 'so valuable, enough, very motivating, more effective, and logical' to evaluate the program. However, they commented on different parts of the curriculum with more caution using hypothetical demand markers such as 'theories may be decreased'. Another example was perceived in response to the role of the arrangement of program phases in their learning to teach. Participants generally used evaluative statements with highintensity value markers such as 'very useful, crucial, great, important issues, practical lessons, and so important' and modal markers like 'could and may'. Table 2 depicts the commitment to modality and evaluation in each phase of the ESA teacher education curriculum. 
Despite significant changes in student teachers' professional identity, inconsistent cases were observed in HE and AF's performances. In line with slow changes in their professional identity, their performances indicated their cautious movements, low tone of voice with several pauses, and hesitant eye contact. In the focus group discussion, frequent use of mental markers, confusion at the beginning of the practicum, and their feeling towards the need for more practices supported their immature level of behavior.. HE stated:

I can't say about my likes and dislikes of teaching because I have not had any experience of teaching. ... I think, our self-confidence has been improved ... .I think, becoming a teacher can be facilitated by more performances and I think, Phase Two should be extended. ... . like the first time, I really didn't want to present any teaching. Then, I got used to it and didn't hate.

Figure 3 depicts the degree of commitment to modality and evaluation across three phases.

\section{Major shifts in TPI through GT}

Three stages of systematic coding guided by Grounded Theory (Glaser \& Strauss, 1967) along with comparing and contrasting meaningful categories several times resulted in identifying three major changes in pre-service TPI during 1 year of practicum.

\section{From commitment to evaluation toward commitment to modality}

Our findings based on pre-course interview, reflective essays, student teachers' observations, and subsequent focus group discussions, indicate that pre-service teachers appear to be more committed to Modality rather than Evaluation at the end of the program. This indicates that they demonstrated greater interest to value language teaching and teachers through using Evaluation markers with high intensity prior to the practicum and evolved to add a substantial number of Modality markers after the practicum to present their commitment to truth, obligation, and necessity as Modality units.

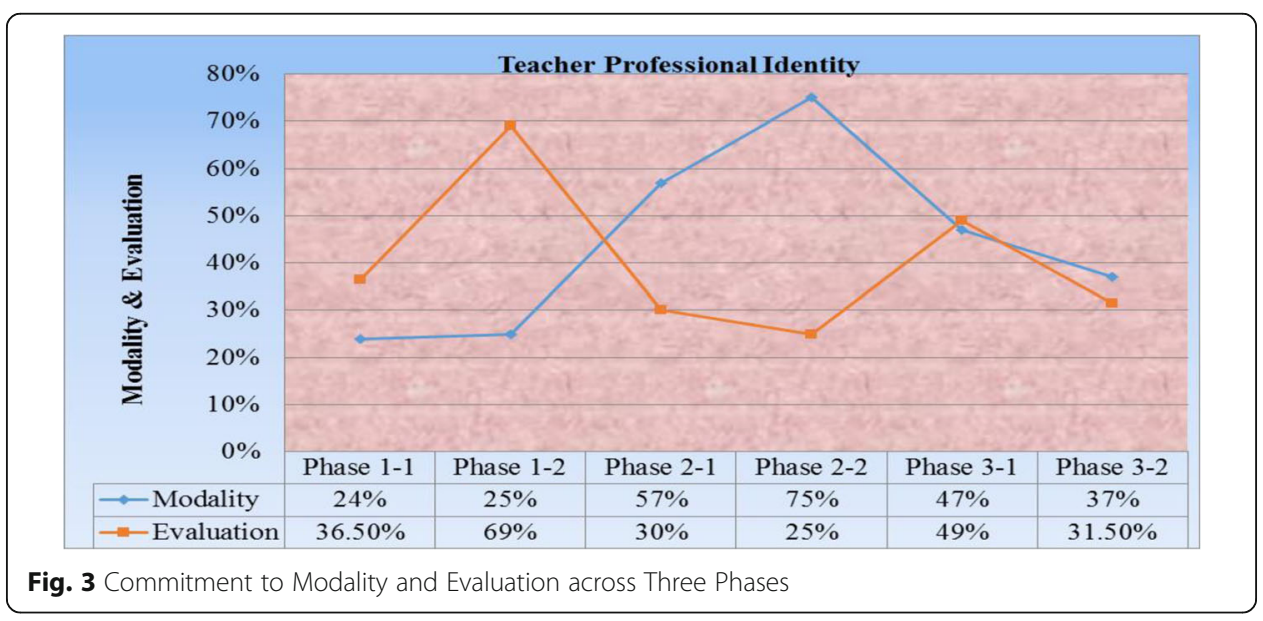


Wenger (1998) argues that the existence of a relationship between identity and practice encourages this continuum of change. Comparing the participants' answers to the pre-course interview and RE1, one can see that most participants shifted the way they displayed their motivation to select teaching as their profession by making evaluative statements toward applying truth and mental processes with more confidence. Acknowledging Kelchtermans' (1993) conceptualization of teacher professional identity, pre-service teachers could easily connect their motives to select teaching with prospective dimensions at the end of the Engage and Study Phases when they engaged with knowledge about language teaching, English language, and teaching practices. The changes in ME's language in displaying her motivation on 'selecting language teaching as a profession' in the pre-course interview and two Reflective Essays, support this movement across the continuum of commitment to evaluation toward a commitment to modality:

Pre-course interview: I would like to know how to be a good teacher, not exactly in an academic way. Maybe in the future, I'll think about it. But for now, I want to be a good English teacher. I liked the class. I thought you would be too serious, but you weren't. I really feel ok about this class.

RE1: I want to be in touch with English. I want to be able to teach English to my own children. I think teaching English can be one of the best careers for a housewife because you can choose your time.

RE2: Everything started for me after the first phase when we started the practical phase. When I saw how they are working on teaching in other countries, I thought about why we should not do the same thing for our own country.

\section{From one-dimensional toward multi-dimensional perception}

EFL Pre-service teachers in the present study favored a multi-dimensional view of language teaching and teachers at the end of the program as compared to their narrower view at the starting point. This finding supports Chong et al.'s (2011), p. 59 argument that pre-service teachers often enter the practicum with a one-dimensional image resulted from their past culture and experiences as students. In fact, their previous identity prevents them from contemplating the multidimensional aspects of their identities as language teachers. The analysis of data revealed that the perception of six out of eight student teachers changed from focusing on one dimension of teaching techniques in observation notes and improved to be able to comment on several components perceiving as the prospective dimensions of their professional selves and future perspective.

For instance, in her first interview, NA referred only to an altruistic aspect of teaching stating "I do think teaching is rewarding. I love it when I see the light in students' eyes." Toward the end of the Engage Phase, she tended to project a type of selfawareness about her motivation for selecting teaching as a profession. She declared "I love teaching. I feel more serious. I realize how complex teaching is. ... Discussions were 
pretty effective." Then, in the second Reflective Essay, she stated that "The important thing is self-awareness. It's not just information. When you enter the class, then, your students are up to you."

Conversely, the same changes were not realized across the program for AF and HE. In addition to the lack of self-confidence, another reason might be the teachers' perception that they lack influence and control of their classroom setting. This perception, real or imagined, might limit their desire to change their instructional approaches, classroom behavior and, consequently, their professional identity development (Korthagen, 2004).

\section{From problem analysis toward problem solving skills}

Our evidence, gained through participants' two reflective essays, observation notes, practicums and focus group discussions, indicates that pre-service teachers began to develop greater ability that was emerged by the problem analysis skills to reflective, and problem solving skills in the classroom contexts.. Then, having been placed in the positions of both learners and prospective teachers, they improved to the point where they could reflect carefully and suggest appropriate solutions for in-service teachers' performances As researchers believe, encouraging professional knowledge in pre-service teachers supports confidence building, and helps develop teaching competence and problem-solving skills (Bukor, 2015; McLean, 2017). In her last reflection, for instance, SA stated that she had started to feel like a teacher with new assessment, reflection, and problem-solving skills. In focus group discussion, when asked about the quality of the program and the technique she would select to teach English, she said:

In studying theories, you first focused on our accuracy at the time of correction. The phases were very motivating. .... phase 2 was really challenging. Now, we can see changes in ourselves. ... In teaching English, the teacher should incorporate the language into stories and actions. When students see the structure in authentic sources, they will learn. Also, I will write some examples on the board.

However, as in previous stages, inconsistent cases were observed in HE and AF that suggested superficial and fewer improvements in their identities. For example, her observation notes display some inconsistencies as she first began her observations by analyzing the situation, but then moved on to simple observations. For instance, she says, "the teacher used L1 in class, she used chain story-telling, and checked students' homework". This suggests that her agency failed to develop. Ideally, she should have transitioned from analysis to problem-solving. Figure 4 displays the changes in professional identity construction of EFL pre-service teachers across the ESA TE curriculum.

\section{Discussion}

\section{Research question one}

The first question in the present study sought to assess the progress of the pre-service TPI development and to assess changes in each phase of the ESA teacher education curriculum. Social constructivists see learning to teach as a social and independent process that new teachers gain through practice and reflection over time. In this trend, 


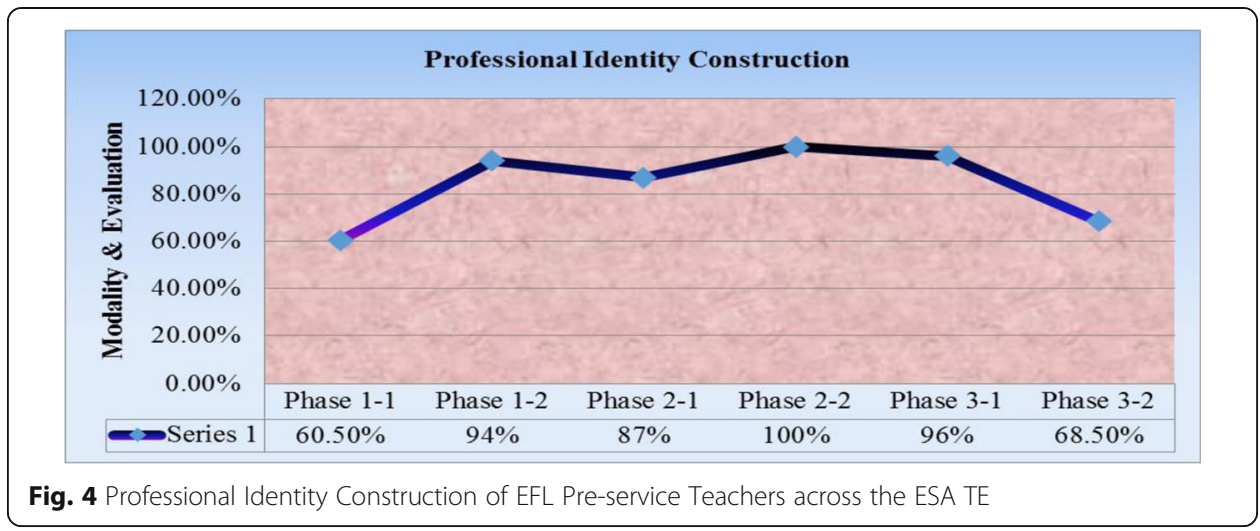

pre-service teachers need to gradually internalize the knowledge of both the process of teaching, and how to become a teacher. Accordingly, constructivism is justified by incorporating varieties of pedagogical practices and interactions such as group and pair interactions, teacher modeling, and teaching performances in educational contexts to engage the student teachers meaningfully and lead them to the construction of their professional identities as a central outcome of this process. However, researchers argue that due to the intricate nature of teacher identity, it is hard to identify the particular features involving in the formation of TPI (Beijaard et al., 2004). Therefore, in the current study, assessment, and analysis of the data guided by triangulation methods such as GT and identity-in-discourse revealed the following changes in each phase.

Regarding the Engage Phase, pre-service teachers used more evaluative markers before the instruction but evolved to using more modality markers after learning and engaging in teaching-related issues. In concert with Mathew and Poehner (2014) who believe in learning through engagement in tasks and assessing learners' challenges and progress over time, the participants also presented teacher identity characteristics such as self-image, self-awareness, and the prospective dimensions of their jobs as teachers when they claimed their learned knowledge and their perception of the Phase One in RE1. This perception and the emergence of these features may have resulted from participating in a professional learning environment and mutual engagement in reflective activities that offer a powerful community of practice and an appropriate opportunity for student teachers to create a new identity. However, surprisingly, this finding conflicts with Prabjandee (2020) who found a passive effect of teacher education in triggering the construction of TPI.

In the Study Phase, the analysis of observation notes and teaching performances revealed the construction of an image of the prospective professional self in the participants. Having identified features of professional identity such as task perception in their observation notes, they promoted their skills from problem analyzing to problemsolving as they provided solutions to the classroom problems. In addition, the gradual changes in professional identities of teacher trainees affected their decision making in selecting activities and teaching behavior in their performances. As a result, self-confidence as a significant feature of teacher identity was observed in teaching practices of almost all pre-service teachers. In this phase, even though the progress of changes was passed moderately, the findings echo Özmen's (2010) argument focusing on the effect of field training on the trainees' behavior. In this phase, pre-service teachers showed 
enhancements in their self-confidence by creating their own techniques in their performances guiding them as they adapted to their new identities as teachers. Most of these changes can be attributed to Wenger's (1998) assertion on the relationship between participants' teaching practices and identity construction. Because the ESA curriculum is circular by nature and each phase introduces its following stages, the emergence of identity features such as self-image, self-awareness, and task perception may support the development of other features such as self-confidence in this phase.

During the Activate Phase, student teachers appeared to align their activities with the characteristics of a good teacher such as being supportive, creative, a planner, motivator, and researcher as they claimed in both RE2 and the focus group. Furthermore, almost all of the participants could predict some aspects of their future job that is aligned with Kelchtermans' (1993) term of teacher professional identity as task perception when they foresaw the challenges of their imaginary classrooms and provided solutions. Another shift of identity appeared in the participants when they progressed in perceiving diverse aspects of teaching and moved from one-dimensional individuals in the Engage Phase to multi-dimensional at the exit point of the practicum. This underscores the fact that, as mentioned above, teacher identity is a multi-dimensional dynamic concept, as typically discovered by pre-service teachers. Teacher identity is an amalgamation of meeting the demands and expectations of the teachers' professional environments (Chong et al., 2011).

\section{Research question two}

In answering the second research question, several influential factors in facilitating the process of shaping Iranian EFL pre-service teachers' professional identity were identified. These factors are mentor's behavior, discourse, and rapport as a role model, trainees' prior experience, passion, engagement, and exposure to teaching materials such as readings, websites, videos, and varieties of educational contexts, and structured performances. Moreover, the mentor's ongoing support appeared to play a central role in helping trainees pass through the Zone of Proximal Development (ZPD) as evidenced by the activities in each phase and supported by Trent (2011) and Izadinia (2013). In addition to previously-mentioned factors, the sequencing of the TE materials and the input from subsequent focus group discussions, led to an effective design of the pre-service TPI.. However, Harlen (2010) strongly recommends productive teacher assessment techniques to understand the progress of transitions over time and highlights the role of assessment techniques in the promotion of the students' active engagement in their learning process.

The findings of the present study are in line with Wenger's (1998) theory of teacher identity construction. He argues that teacher identity develops through practice in a teaching environment, and evolves through engagement with students, designing problem-solving techniques and re-alignment of skills to deal with new challenges.

This supports the idea that ESA teacher education can develop engagement to foster a sense of belonging in the Engage Phase. It can help pre-service teachers construct an image of their selves by doing, learning, and belonging in the Study Phase, and bring their shared understanding and practices into alignment in the Activate Phase. As mentioned in the previous sections, at the end of the program, pre-service teachers could 
complete the practicum by consolidating their understanding of the three phases to shape their identity as a language teacher that might have been benefitted from Wenger's modes in shaping teacher identity. This can provide support for the capacity of the ESA teacher education curriculum to assist pre-service teachers in managing tensions and transferring them to positive abilities in teaching.

The findings also evidenced the critical role of integrating theory and practice in the process of TPI construction (Chong et al., 2011; Korthagen et al., 2006; Prabjandee, 2020). An additional lens of the present study echoed Kumaravadivelu (2012) Modular Model which consists of integrated modules of knowing, analysing, recognizing, doing, and seeing, led a shift, from traditional transmission approach to one based on poststructuralists' theory, and this in turn, led to a gradual transformation of the Iranian English as a Foreign Language (EFL) pre-service TPI.

Although the research has demonstrated the process of identity formation in Iranian EFL pre-service teachers, several caveats need to be mentioned in the present study. First, the ESA curriculum was designed for preparing professional teachers in an institute in Iran and the sampling type was based on recruitment by the office staff and all participants were female. That may cause a difference in teacher identity formation while engaged in course activities and participating in community practice. Second, the current study was limited by institutional principles. Therefore, the first actual classes of pre-service teachers after graduation could not be videotaped to explore the continuity of professional identity construction and to observe whether they incorporate the learned materials in their teaching. Finally, caution should be applied in transferring the findings due to the limited number of participants and the local context of the study.

Certainly, more research needs to be conducted to uncover the realities of the complex concept of EFL teachers' professional identity and the mechanisms for assessing its progress. The findings provide the following grounds for further research: (a) a future study can assess teacher identity construction with the same curriculum in different institutes in Iran and with a localized version of the program in other countries, (b) there may be an interesting area of research if future researchers assess TPI in two groups of males and females to examine gender differences in this regard, (c) a further work is required to explore the follow-up videos from the initial classes of the same student teachers for a quality assessment of the on-going process of the variations of professional identity construction in student teachers, and (d) further investigations are needed to assess the professional identity of EFL pre-service teachers in an online ESA teacher education environment to compare the findings with that of the current study.

Implications of the current study suggest a significant role for three groups of educators. Teacher educators are recommended to devote significant attention to their behavior as role models and a catalyst to help student teachers pass through the stages of identity formation. Moreover, they can assess the process of identity construction and the teaching quality of student teachers by collecting effective portfolio data as an assessment tool.

Pre-service TE curriculum designers ought to design local programs matched with the present and future needs of the pre-service teachers. In this way, if curriculum designers are seeking a program to mediate TPI development that is comprehensive and reflective, the findings of the present study suggest the ESA program be appropriate for 
both assessing and triggering the construction of teacher identities. Moreover, ESA curriculum can provide a space for addressing the concerns of previous researchers who believed that current teacher education in Iran does not take into account trainees' real needs, lacks opportunities to practice and observe teaching during the course, and does not have a comprehensive and pertinent syllabus (Ganji et al., 2018). Ideally, EFL teacher education curriculum designers should include a balance between theoretical and procedural knowledge and provide an efficient platform for student teachers to perform actions, negotiate, and learn.

Finally, stakeholders such as institutional authorities ought to encourage trainers and curriculum developers in facilitating the process of professional identity construction leading to a successful outcome. However, for a wider application of the ESA teacher education curriculum, they need to develop supportive strategies to ensure that stakeholders provide an appropriate environment for student teachers and teacher educators.

\section{Conclusions}

The contribution of the ESA teacher education curriculum to the process of professional identity construction of EFL Pre-service teachers in Iran included early signs of changes in the Engage Phase. This indicates the critical role of engagement in learning about language and language teaching methodologies at the initial steps of identity formation. The student teachers' high level of commitment in the Study Phase supported the importance of including the integration of theoretical and practical levels of contents in the TE curriculum. To enable the student teachers to sustain the identity level they obtained in previous stages, they need to activate a circular knowledge of learning to teach at the last stage. Furthermore, the current study revealed that observation checklists can be served as both learning and assessment tools in TE programs.

Encouraged by the recommendations of earlier studies, the findings of the present study suggest that the TE curriculum in Iran needs to be revised and redesigned. Throughout this revision, TE curriculum designers need to keep in mind the importance of the time required for the developmental stages of professional identity construction to help pre-service teachers pass through the steps of learning to teach and to become teachers. To arrive at a clear view of the self as a teacher and the transition from a student to a teacher are not sudden phenomena. This necessitates that teacher educators notice the tensions student teachers experience during the prolonged process of learning to commit themselves as language teachers. A stage by stage training of teachers along with a careful sequencing of materials and activities matching the realistic contexts can facilitate identity construction in pre-service teachers. In addition, the creation of an ESA teacher education curriculum, with precise assessment guidelines, may assist pre-service teachers in going through the stages of ZPD to become effective teachers, who would continue to learn and evolve to meet the demands of their professional environments.

\section{Abbreviations}

EFL: English as a Foreign language; ESA: Engage, Study, Activate; GT: Grounded Theory; MSRT: Ministry of Science, Research, and Technology; RE1: Reflective Essay One; RE2: Reflective Essay Two; TE: Teacher Education; TPI: Teacher Professional Identity; ZPD: Zone of Proximal Development 


\section{Acknowledgements}

We would like to thank the reviewers of Asian-Pacific Journal of Second and Foreign Language Education for their helpful comments on the earlier version of the paper. We are also thankful to Mr. Damon Chevrier for the careful proofreading of the manuscript.

\section{Authors' contributions}

Dr. Chalak was the supervisor and guided the project. Ms. Haghighi Irani conducted the research, collected, analyzed, and interpreted the data. She produced the paper and revised it according to Dr. Chalak and Dr. Heidari Tabrizi's comments. Then, the authors read and approved the final manuscript.

\section{Funding}

No grant or fund has been received by the authors.

\section{Availability of data and materials}

The datasets used and/or analyzed during the current study are available from the corresponding author on reasonable request.

\section{Competing interests}

There is no competing interest.

Received: 5 May 2020 Accepted: 17 September 2020

Published online: 01 October 2020

\section{References}

Abbasian, G. R., \& Karbalaee Esmailee, M. (2018). Peer-coaching, EFL teacher's professional identity development, and students' academic achievements. Theory and Practice in Language Studies, 8(1), 150-163.

Abednia, A. (2012). Teachers' professional identity: Contributions of a critical EFL teacher education course in Iran. Teaching and Teacher Education, 28(3), 706-717.

Abednia, A., Hovassapian, A., Teimournezhad, S., \& Ghanbari, N. (2013). Reflection journal writing: Exploring EFL teachers' perceptions. System, 41, 503-514.

Antonek, J. L., McCormick, D. E., \& Donato, R. (1997). The student-teacher portfolio as autobiography: Developing a professional identity. The Modern Language Journal, 81, 15-27.

Ary, D., Jacobs, L. C., Irvine, C. K. S., \& Walker, D. A. (2019). Introduction to research in education, (10th ed., ). Boston: Cengage. Beauchamp, C., \& Thomas, L. (2009). Understanding teacher identity: An overview of issues in the literature and implications for teacher education. Cambridge Journal of Education, 39(2), 175-189.

Beijaard, D., Meijer, P. C., \& Verloop, N. (2004). Reconsidering research on teachers' professional identity. Teaching and Teacher Education, 20(1), 107-128.

Bigelow, M., \& Walker, C. L. (2004). Creating a teacher community: research and practice in language teacher education. In M. H. Bigelow, \& C. L. Walker (Eds.), Creating teacher community: selected papers from the third international conference on Language Teacher Education (1-26). Minneapolis: The University of Minnesota.

Birello, M., Royer, C., \& Pluvient, D. (2011). Reflective journals: A tool for the professional development of language teachers. Language Awareness in Teacher Education, 13, 79-94.

Bukor, E. (2015). Exploring teacher identity from a holistic perspective: Reconstructing and reconnecting personal and professional selves. Teachers and Teaching: Theory and Practice, 21(3), 305-327.

Cattley, G. (2007). Emergence of professional identity for the pre-service teacher. International Education Journal, 8(2), 337347.

Chong, S., Low, E. L., \& Goh, K. C. (2011). Emerging professional identity of pre-service teachers. Australian Journal of Teacher Education, 36(8), 50-64.

Dörnyei, Z. (2007). Research methods in applied linguistics. Oxford: Oxford University Press.

Fairclough, N. (2003). Analyzing discourse. Textual analysis for social research. London: Routledge.

Farrell, T. S. C. (2011). Exploring the professional role identities of experienced ESL teachers through reflective practice. System, 39, 54-62.

Freeman, D. (1989). Teacher training, development, and decision making: A model of teaching and related strategies for language teacher education. TESOL Quarterly, 23(1), 27-45.

Friesen, M. D., \& Besley, S. C. (2013). Teacher identity development in the first year of teacher education: A developmental and social psychological perspective. Teaching and Teacher Education, 36, 23-32. https://doi.org/10.1016/j.tate.2013.06.005

Ganji, M., Ketabi, S., \& Shahnazari, M. (2018). Teacher training courses in Iranian private language institutes: Issues and options. Issues in Educational Research, 28(2), 367-384 http://www.iier.org.au/iier28/ganji.pdf.

Glaser, B. G., \& Strauss, A. L. (1967). The discovery of grounded theory. Strategies for qualitative research. Chicago: Aldine Pub.

Hanna, F., Oostdam, R., Severiens, S. E., \& Zijlstra, B. J. (2019). Domains of teacher identity: A review of quantitative measurement instruments. Educational Research Review, 27, 15-27. https://doi.org/10.1016/j.edurev.2019.01.003.

Hanna, F., Oostdam, R., Severiens, S. E., \& Zijlstra, B. J. (2020). Assessing the professional identity of primary student teachers: Design and validation of the teacher identity measurement scale. Studies in Educational Evaluation, 64(100822), 1-10. https://doi.org/10.1016/j.stueduc.2019.100822.

Harlen, W. (2010). What is quality teacher assessment? Principles of assessment practice. In J. Gardner, W. Harlen, L. Hayward, G. Stobart, \& M. Montgomery (Eds.), Developing teacher assessment, (pp. 29-52). London: Open University Press.

Izadinia, M. (2013). A review of research on student teachers' professional identity. British Educational Research Journal, 39(4), $694-713$.

Kanno, Y., \& Stuart, C. (2011). Learning to become a second language teacher: Identities-in-practice. The Modern Language Journal, 95(ii), 236-252. 
Kelchtermans, G. (1993). Getting the story, understanding the lives. From career stories to teachers' professional development. Teaching and Teacher Education, 9, 443-456.

Kennedy, C. (2015). Innovations, trends and challenges. London: British Council.

Korthagen, F., Loughran, J., \& Russell, T. (2006). Developing fundamental principles for teacher education programs and practices. Teaching and Teacher Education, 22, 1020-1041.

Korthagen, F. A. J. (2004). In search of the essence of a good teacher: Towards a more holistic approach in teacher education. Teaching and Teacher Education, 20(1), 77-97.

Kumaravadivelu, B. (2012). Language teacher education for a global society. New York: Routledge

Lee, H. J. (2005). Understanding and assessing pre-service teachers' reflective thinking. Teaching and Teacher Education, 21, 699-715.

Mackey, A., \& Gass, S. M. (2005). Second language research: Methodology and design. New Jersey: Lawrence Erlbaum Association.

Maclean, R., \& White, S. (2007). Video reflection and the formation of teacher identity in a team of pre-service and experienced teachers. Reflective Practice, 8(1), 47-60.

Mathew, R., \& Poehner, M. E. (2014). Monitoring progress in the classroom. In A. J. Kunnan (Ed.), The companion to language assessment, (1st ed., pp. 1-15). Wiley.

McLean, K. (2017). Using reflective practice to foster confidence and competence to teach literacy in primary schools. In K. McLean (Ed.), Reflective theory, and practice in teacher education, (pp. 120-137). Singapore: Springer.

Motallebzadeh, K., \& Kazemi, B. (2018). The relationship between EFL teachers' professional identity and their self-esteem. Cogent Education, 5, 1-9. https://doi.org/10.1080/2331186X.2018.1443374.

Naseri Karimvand, P., Hessamy, G., \& Hemmati, F. (2014). The place of postmethod pedagogy in teacher education programs in EFL language centers of Iran. Iranian Journal of Applied Linguistics (IJAL), 17(2), 59-91.

Nezakat-Alhosseini, M., \& Ketabi, S. (2013). Teacher training system and EFL classes in Iran. Social and Behavioral Sciences, 70 526-536.

Özmen, K. S. (2010). Fostering nonverbal immediacy and teacher identity through an acting course in English teacher education. Australian Journal of Teacher Education, 35(6), 1-23.

Palmer, P. J. (1998). The courage to teach: Exploring the inner landscape of a teacher's life. San Francisco: Jossey-Bass Publishers.

Pennington, M. C., \& Richards, J. C. (2016). Teacher identity in language teaching: Integrating personal, contextual, and professional factors. RELC Journal, 1-19. https://doi.org/10.1177/0033688216631219.

Prabjandee, D. (2020). Narratives of learning to become English teachers in Thailand: Developing identity through a teacher education program. Teacher Development. https://doi.org/10.1080/13664530.2019.1699155.

Rashidi, N., \& Mansourzadeh, N. (2017). Postmethod pedagogy and Iranian EFL teachers' understandings: Is a promising trend on the way? Issues in Language Teaching (ILT), 6(1), 55-82.

Riazi, A. M. (2016). The routledge encyclopedia of research methods in applied linguistics: Quantitative, qualitative, and mixed methods research. New York: Routledge.

Sardabi, N., Biria, R., \& Ameri Golestan, A. (2018). Reshaping teacher professional identity through critical pedagogy-informed teacher education. International Journal of Instruction, 11(3), 617-634.

Tajeddin, Z., \& Khodarahmi, E. (2013). EFL teachers' professional identity: Underlying components and factors contributing to its construction. Mashhad: Paper presented in the 11th TELLSI international conference, Tabaran Institute of Higher Education.

Tao, J., \& Gao, X. (2018). Identity constructions of ESP teachers in a Chinese university. English for Specific Purposes, $49,1-13$.

Trent, J. (2010). Teacher education as identity construction: Insights from action research. Journal of Education for Teaching, $36(2), 153-168$.

Trent, J. (2011). Four years on, I'm ready to teach': Teacher education and the construction of teacher identities. Teachers and Teaching, 17(5), 529-543.

Trent, J., \& Shroff, R. H. (2013). Technology, identity, and community: The role of electronic teaching portfolios in becoming a teacher. Technology, Pedagogy and Education, 22(1), 3-20.

Van der Wal, M. M., Oolbekkink-Marchand, H. W., Schaap, H., \& Meijer, P. C. (2019). Impact of early career teachers' professional identity tensions. Teaching and Teacher Education, 80, 59-70. https://doi.org/10.1016/j.tate.2019.01.001.

Varghese, M., Morgan, B., Johnston, B., \& Johnson, K. A. (2005). Theorizing language teacher identity: Three perspectives and beyond. Journal of Language, Identity, and Education, 4(1), 21-44.

Wenger, E. (1998). Communities of practice: Learning, meaning, and identity. Cambridge: Cambridge University Press.

Yazan, B. (2019). Toward identity-oriented teacher education: Critical autoethnographic narrative. TESOL Journal, 10(e00388), 1-15. https://doi.org/10.1002/tesj.388.

Yuan, R., \& Lee, I. (2014). The cognitive, social, and emotional processes of teacher identity construction in a pre-service teacher education program. Research Papers in Education, 30(4), 469-491.

\section{Publisher's Note}

Springer Nature remains neutral with regard to jurisdictional claims in published maps and institutional affiliations. 